\title{
The treatment of varicose leg ulcers by hyperbaric oxygen
}

\author{
B. H. BASS \\ M.D., M.R.C.P. \\ Consultant Physician, Good Hope General Hospital, \\ Sutton Coldfield, Warwickshire
}

\begin{abstract}
Summary
Hyperbaric oxygen at 2 atmospheres pressure was administered to nineteen cases of chronic varicose leg ulceration. Treatment was given for $2 \mathrm{hr}$ on 5 days of each week. Bacterial infection of the ulcers was suppressed, and drying of the lesions occurred within hours of commencing treatment. Epithelialization of healthy granulation tissue was a constant feature. Simple venous ulcers consistently responded better than those cases where arterial insufficiency was present. No adverse reactions were observed. Seventeen of the nineteen patients had their ulcers healed after a mean exposure to OHP of $60.7 \mathrm{hr}$.
\end{abstract}

\section{Introduction}

Varicose ulcers of the legs are common, disabling and often chronic. Their resistance to treatment either by surgery or local applications is such as to make sufferers from the condition to be like the poor-always with us, haunting varicose vein clinics and family doctors.

For the last 2 years another method of treatment has been tried out at Good Hope General Hospital. This paper is an account of the method, using hyperbaric oxygen at 2 atmospheres pressure together with the results obtained on nineteen patients.

\section{The patients}

These were to some extent selected in that they had all received more conventional treatment in the past. Some had been treated by ligation of their varicose veins. Others had the veins stripped and ligation of the deep perforating branches around the ankle.

All had received lengthy topical treatment with various pastes, plus or minus compression bandaging. The length of time for which the ulcers had been present varied from 5 to more than 20 years (Mean $10 \cdot 1$ years). Thirteen of the patients were female, illustrating the preponderance of women suffering from varicose veins, and the mean age of the patients was 53.6 years. The oldest patient was a woman of
80 years who tolerated hyperbaric oxygen surprisingly well. No controls were used since the patients were deemed to act as their own controls in that they had not responded to other forms of therapy over many years.

\section{Method}

The Vickers 'Lotus' hyperbaric bed was employed. This uses pure oxygen at 2 atmospheres pressure. Exposure was for $2 \mathrm{hr}$ daily for 5 days each week, and wherever possible, on an outpatient basis by appointment. A State Enrolled Nurse supervised all treatments, and the patients were never left unattended at any time during exposure.

All ulcers were photographed and measured at the onset of treatment, during the course, and afterwards. Swabs were taken from the ulcers from time to time in order to observe the effect of the hyperbaric oxygen on infecting organisms.

The only other form of treatment given to the patients was either a simple dry gauze dressing, or red lotion plus a dry dressing.

\section{Results}

Varicose ulcers healed rapidly. Seventeen of the patients were eventually discharged with complete healing. Where there was much accompanying sepsis the healing process was delayed, although bacteriostasis was observed at 2 atmospheres. The commonest infecting organisms were Streptococcus faecalis, Escherichia coli and Staphylococcus aureus in that order. No case of cross infection within the chamber was encountered.

All the patients have been personally followed up, and to date all ulcers which healed have remained so. Drying occurs visibly after the first $2 \mathrm{hr}$ exposure, and the new skin which grows in from the periphery of the ulcer has a healthy pink colour in marked contrast to the indolent blue margins of the ulcers prior to commencement of hyperbaric oxygen.

When arterial insufficiency was present, the results were much less satisfactory. This group has been 
TABLE 1

\begin{tabular}{rllccl}
\hline Case No. & Age & Sex & $\begin{array}{c}\text { Length of history } \\
\text { (years) }\end{array}$ & $\begin{array}{c}\text { Duration of exposure } \\
\text { at 2 atmospheres (hr) }\end{array}$ & Results \\
\hline 1 & 35 & F & 6 & 30 & Healed. \\
2 & 76 & M & 12 & 16 & Healed. \\
3 & 80 & F & $>20$ & 144 & Giant ulcer, 95\% healed. \\
4 & 46 & F & 8 & 38 & Healed. \\
5 & 72 & F & 15 & 10 & Healed. \\
6 & 67 & F & 10 & 68 & Healed. \\
7 & 70 & F & 12 & 48 & Healed. \\
8 & 71 & F & $>20$ & 104 & Slow healing. \\
9 & 67 & F & 13 & 68 & Healed. \\
10 & 35 & M & 6 & 200 & Venous ulcer healed rapidly, \\
& & & & 56 & arterial ulcer slow to heal. \\
11 & 60 & Healed. \\
12 & 41 & M & 8 & 18 & Healed. \\
13 & 59 & F & 7 & 36 & Healed. \\
14 & 61 & F & 7 & 30 & Healed. \\
15 & 60 & M & 11 & 78 & Slow healing, much sepsis. \\
16 & 47 & F & 5 & 80 & Uncooperative, poor result. \\
17 & 44 & F & 9 & 42 & Healed. \\
18 & 63 & F & 8 & 36 & Healed. \\
19 & 34 & M & 10 & 64 & Healed. \\
Average: & $53 \cdot 6$ & & 5 & $60 \cdot 7$ & \\
\hline
\end{tabular}

excluded from the present series, but experience leads me to believe that so called 'arterial' ulcers of the lower limbs are unsuitable for treatment with hyperbaric oxygen.

\section{Discussion}

Several authors (Smith, 1961; Beckham, 1965; Slack, 1966) have reported on the beneficial effect of hyperbaric oxygen (OHP) on wounds and skin lesions. A recent paper by Fischer (1969) gives an account of topical OHP in the treatment of varicose ulcers and pressure sores. Fischer found that infection of the ulcers was suppressed, and commented upon the enhanced healing observed. The pink colour which I have observed is commented on and the rapid drying of the ulcers confirmed.

The use of pure oxygen obviates the risk of 'the bends', as no nitrogen is breathed, and by using oxygen at only 2 atmospheres for $2 \mathrm{hr}$ exposures only, the risks of oxygen toxicity are minimized. Stringent fire precautions are observed.

No untoward reactions were encountered in the present series, although patients with a history of middle ear disease were excluded because of the risk of barotrauma.
New methods of treatment are often hailed as panaceas and it is difficult not to feel optimistic in the light of the very good results observed in the present series. Nevertheless, treatment by this method is lengthy, costly and wasteful of nurses' time, since the patient is at no time left unattended. However, the gratitude of the patients, many of whom had given up hope of ever having their ulcers healed, is more than adequate compensation.

\section{Acknowledgments}

It is a pleasure to thank the Nursing Staff at Good Hope General Hospital, without whose enthusiastic co-operation, this study could not have been made, and also Messrs Vickers for their generous help in the reproduction of the colour photographs.

\section{References}

BeCKHAM, P.H. (1965) Effect of hyperbaric oxygenation on wound strength in dogs. Hyperbaric Oxygenation, p. 397. Livingstone, Edinburgh.

Fischer, B.H. (1969) Topical hyperbaric oxygen treatment of pressure sores and skin ulcers. Lancet, ii, 405.

SLACK, W.K. (1966) The effect of hyperbaric oxygen at 2 atmospheres on the healing of gravitational and varicose ulcers. Hospital Practice, 1, 42.

SмITH, G. (1961) Near avulsion of foot treated by replacement and subsequent prolonged exposure of patient to oxygen at 2 atmospheres pressure. Lancet, ii, 1122. 

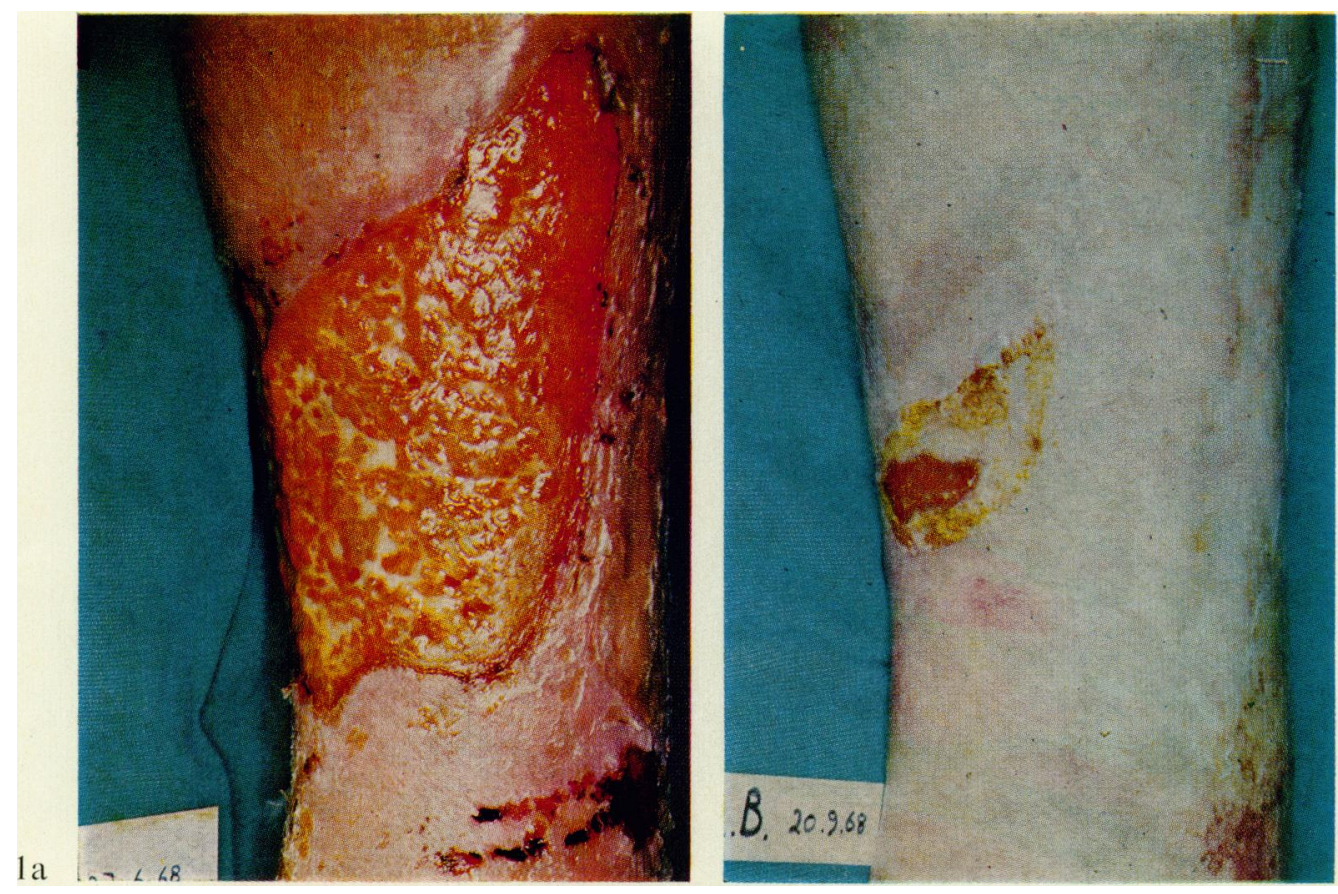

Plate 1. (a) (Patient No. 3) Giant infected circumferential valicose ulcer of more than 20 years' duration. (b) Patient No. 3 after $144 \mathrm{hr}$ exposure to 2 atmospheres of hyperbaric oxygen. The ulcer has all but healed. Note the healthy appearance of the new skin.

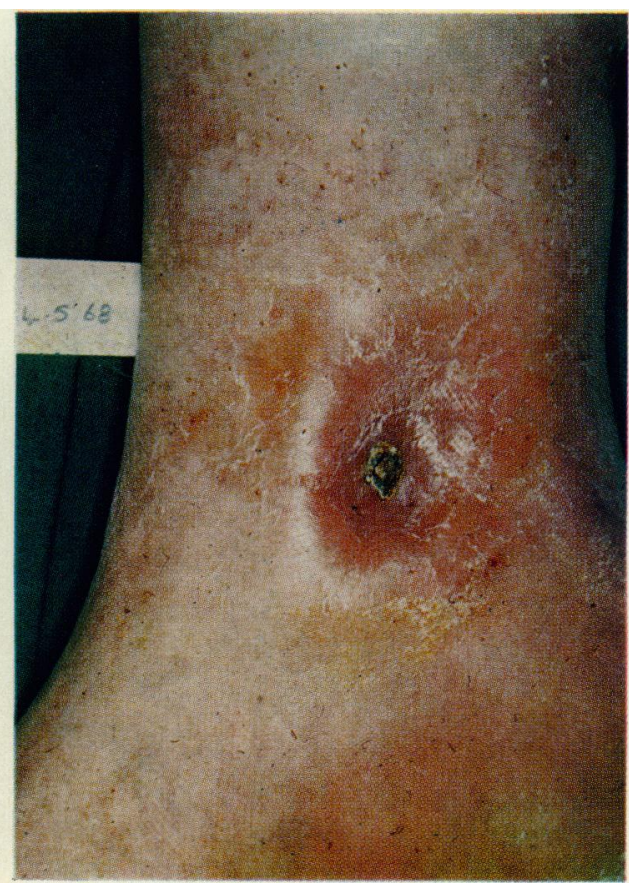

$1 b$

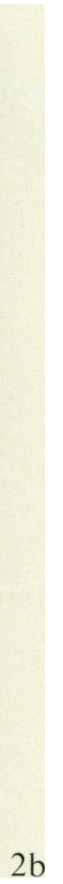

Plate 2. (a) (Patient No. 12) Varicose ulcer on medial aspect of leg. Present for 7 years. (b) After $18 \mathrm{hr}$ exposure to 2 atmospheres hyperbaric oxygen, the ulcer has healed leaving a small central scar which later separated. 